\title{
Associations of Insulin Resistance With Cardiovascular Risk Factors and Inflammatory Cytokines in Normal- Weight Hispanic Women
}

\author{
Chantal A. Vella, PHD $^{1}$ \\ Ximena Burgos, Ms ${ }^{2}$ \\ Carla J. Ellis, $\mathrm{RN}^{2}$ \\ RAul Y. Zubia, Ms ${ }^{2}$
}

OBJECTIVE-To investigate the associations of markers of insulin resistance with cardiovascular disease risk factors and inflammation in young, normal-weight, Hispanic women.

RESEARCH DESICN AND METHODS - Seventy-one normal-weight (BMI $<25 \mathrm{~kg} / \mathrm{m}^{2}$ ) Hispanic women (age, 20-39 years) participated in a fasting blood draw for glucose, insulin, lipids, and inflammatory markers; a glucose tolerance test; anthropometric and blood pressure measurements; body composition by dual-energy x-ray absorptiometry; and measurements of cardiorespiratory fitness via $\mathrm{VO}_{2 \max }$ and daily physical activity by accelerometer.

RESULTS-Six percent of participants had impaired fasting glucose, 14\% had impaired glucose tolerance, and $48 \%$ had at least one cardiovascular disease risk factor. Homeostasis model assessment of insulin resistance (HOMA-IR) and fasting insulin were positively correlated with glucose, triglycerides, systolic blood pressure, and diastolic blood pressure, and were negatively correlated with adiponectin $(P<0.05)$. The 2 -h insulin was positively correlated with diastolic blood pressure, triglycerides, and high-sensitivity C-reactive protein. HOMA-IR and fasting insulin remained significantly and positively related to glucose, triglycerides, and blood pressure after adjustment for body composition. The relationships between markers of insulin resistance and adiponectin and highsensitivity C-reactive protein were attenuated after adjustment for body composition.

CONCLUSIONS - Surrogate markers of insulin resistance were associated with cardiovascular disease risk factors and inflammation in young, normal-weight, Hispanic women. Our findings suggest that HOMA-IR, fasting, and 2-h insulin may be important clinical markers for identifying young, normal-weight, Hispanic women who may be at risk for development of type 2 diabetes and cardiovascular disease. Our findings show the importance of early screening for prevention of type 2 diabetes and cardiovascular disease in this population.

Diabetes Care 36:1377-1383, 2013

$\mathbf{T}$ he association between insulin resistance and risk of cardiovascular disease has been studied in multiethnic samples in large prospective studies, yet an equivocal relationship has not been established $(1,2)$. Several prospective studies have demonstrated significant associations between insulin resistance and subsequent risk of cardiovascular disease outcomes in Hispanic (3), African American, and Caucasian (4) adults, whereas other studies have failed to consistently demonstrate a significant relationship between insulin resistance and the development of cardiovascular disease (2). Inconsistencies in the literature may be explained by differences in the ethnic group studied, because ethnic background may moderate the relationship between insulin resistance and cardiovascular disease outcomes (1).

In cross-sectional studies, significant relationships have been shown between insulin resistance and individual cardiovascular disease risk factors and markers of

\footnotetext{
$\bullet \bullet \bullet \bullet \bullet \bullet \bullet \bullet \bullet \bullet \bullet \bullet \bullet \bullet \bullet \bullet \bullet \bullet \bullet \bullet \bullet \bullet \bullet \bullet \bullet \bullet \bullet \bullet \bullet \bullet \bullet \bullet \bullet \bullet \bullet \bullet \bullet \bullet \bullet \bullet \bullet \bullet \bullet \bullet \bullet \bullet \bullet \bullet \bullet$

From the ${ }^{1}$ Department of Movement Sciences, University of Idaho, Moscow, Idaho; and the ${ }^{2}$ Department of Kinesiology, University of Texas at El Paso, El Paso, Texas.

Corresponding author: Chantal A. Vella, cvella@uidaho.edu.

Received 1 August 2012 and accepted 4 November 2012.

DOI: $10.2337 / \mathrm{dc} 12-1550$

(C) 2013 by the American Diabetes Association. Readers may use this article as long as the work is properly cited, the use is educational and not for profit, and the work is not altered. See http://creativecommons.org/ licenses/by-nc-nd/3.0/ for details.
}

inflammation in multiethnic samples. For example, insulin resistance was related to dyslipidemia in Asian Indians (5) and Japanese adults (6), to blood pressure in Asian Indians (5) and Chinese adults (7), to markers of inflammation in Caucasian (8), Hispanic, and African American adults $(3,9)$, and to central obesity in Caucasian (10) and Japanese (6) adults. However, the majority of these studies included middle-aged, overweight, and obese subjects, with very few studies including young women, normalweight women, or Hispanic women.

Hispanic women have a lower insulin sensitivity (11) and higher prevalence of metabolic syndrome (12), type 2 diabetes (13), and cardiovascular disease risk factors $(14,15)$ compared with non-Hispanic white women. Large population-based studies indicate that the presence of a single cardiovascular disease risk factor during young adulthood to middle age is associated with an increased lifetime risk for cardiovascular disease and lower survival rate $(16,17)$. Thus, understanding the relationships between insulin resistance and individual risk factors in young Hispanic women is of growing importance for developing early prevention efforts. Moreover, disease in young, normal-weight, Hispanic women may go undetected and undiagnosed for years because of their normal BMI and young age. Therefore, our study investigated whether markers of insulin resistance were related to individual cardiovascular disease risk factors and markers of inflammation in young, normal-weight, Hispanic women. We hypothesized that although the women were normal-weight, markers of insulin resistance would be significantly related to cardiovascular risk factors and inflammation, independent of body composition, in this sample.

\section{RESEARCH DESIGN AND METHODS}

\section{Participants}

Seventy-one young, normal-weight women of Mexican descent, aged 20-39 years, participated in the study. Participants 
were recruited from the University of Texas at El Paso community and surrounding communities of the United States and Mexico border through posted flyers, word of mouth, and university newspaper advertisements. Ethnicity was assessed by self-report and a woman was considered Hispanic if she identified both parents and at least 3 grandparents as Hispanic; all women were of Mexican origin. Participants were tested during the follicular phase of their menstrual cycle as determined by self-report (within 10 days of the start of menstruation). Participants were excluded if they had any of the following characteristics: currently using antihypertensive medication or lipidlowering medications; major systemic disease (e.g., cancer); current pregnancy; diabetes mellitus; cardiovascular disease, including chest pain, myocardial infarction, valvular diseases, ventricular arrhythmias, and heart failure; family history of premature heart disease (e.g., first-degree relative had a fatal or nonfatal heart attack or coronary revascularization before 55 years of age); endocrine disease (e.g., thyroid disease); irregular menstrual cycles; exercise-induced asthma; engaged in smoking within the last 6 months; or unable to perform exercise testing. The study was approved by the University of Texas at El Paso Institutional Review Board.

\section{Sequence of tests}

After reading and signing the consent form, each participant was invited to the laboratory on two occasions for a series of testing. For the first visit, participants were instructed to report to the laboratory after a 12-h fast and to abstain from exercise for $48 \mathrm{~h}$. During this visit, testing included anthropometric and blood pressure measurements and a 2-h oral glucose tolerance test. At the end of the visit, the participant was instructed on the accelerometer protocol. The second visit was scheduled after the participant wore the accelerometer for 7 days and included body composition and cardiorespiratory fitness testing $\left(\mathrm{VO}_{2}\right.$ peak).

Height was recorded to the nearest $0.1 \mathrm{~cm}$ as the average of two measurements using a wall-mounted stadiometer (Seca 220). Body mass was obtained using a calibrated digital scale to the nearest $0.1 \mathrm{~kg}$ (Tanita TBF-310). BMI was calculated as weight in kilograms divided by height in meters squared. Normal weight was defined as BMI 18.5 to $24.9 \mathrm{~kg} / \mathrm{m}^{2}$ (18). After $5 \mathrm{~min}$ of seated rest, two readings of blood pressure, separated by 2 min, were averaged. If the first two readings differed by $>5$ $\mathrm{mmHg}$, then additional readings were obtained and two readings within $5 \mathrm{mmHg}$ were averaged.

\section{Risk factors and inflammatory markers}

Cardiovascular disease risk factors were defined by the criteria set forth by the National Cholesterol Education Program Adult Treatment Panel III Guidelines (19) for diagnosing metabolic syndrome, a precursor to cardiovascular disease. Risk factors included triglycerides $\geq 1.7$ $\mathrm{mmol} / \mathrm{L}$, HDL cholesterol $<1.3 \mathrm{mmol} / \mathrm{L}$, systolic blood pressure $\geq 130 \mathrm{mmHg}$, diastolic blood pressure $\geq 85 \mathrm{mmHg}$, and glucose $\geq 5.6 \mathrm{mmol} / \mathrm{L}(19,20)$. Impaired fasting glucose was defined as a fasting blood glucose value 5.6-6.9 mmol/L. Impaired glucose tolerance was defined as a 2-h postchallenge glucose value of 7.8$11.0 \mathrm{mmol} / \mathrm{L}$. Inflammatory markers measured in the study included highsensitivity C-reactive protein (hs-CRP), tumor necrosis factor $\alpha(\mathrm{TNF}-\alpha)$, interleukin 6 (IL-6), and adiponectin. These inflammatory markers were chosen because they have been causally linked to insulin resistance, metabolic syndrome, type 2 diabetes, and the complications that emerge from these pathologies, including cardiovascular disease $(21,22)$, and have been shown to improve prediction of cardiovascular disease risk compared with models based on lipid levels alone (23).

\section{Oral glucose tolerance testing}

Before the oral glucose tolerance test, a small polyethylene catheter was placed into an anticubital vein and blood samples were collected at baseline ( $0 \mathrm{~min})$, $30,60,90$, and $120 \mathrm{~min}$ for the measurement of serum glucose and insulin concentrations. All oral glucose tolerance tests were performed during the morning after $12 \mathrm{~h}$ of fasting. A baseline blood sample was drawn for assaying glucose, insulin, lipids (HDL cholesterol, triglycerides), and inflammatory markers. Participants were then administered an oral standard load of $75 \mathrm{~g}$ glucose and asked to consume the entire drink within 5 min. Blood samples for each time point were allowed to clot, then were centrifuged, then serum was transferred to cryovials, and the samples were frozen at $-80^{\circ} \mathrm{C}$ for future analysis.

Frozen serum samples were sent to the University of Alabama Center for
Clinical and Translational Sciences for analysis. Glucose was measured by the glucose oxidase method (Sirrus Clinical Chemistry Analyzer; Stanbio Laboratory, Boerne, TX). Insulin was measured using an immunoenzymatic method (TOSOH AIA-600 II analyzer; TOSOH Bioscience, South San Francisco, CA). This assay had a minimum sensitivity of $1.0 \mu \mathrm{U} / \mathrm{mL}$, interassay coefficient of variation $(\mathrm{CV})$ of $4.42 \%$, and intra-assay CV of $1.49 \%$. HDL cholesterol was measured using the colorimetric method with a two-reagent system (Sirrus Clinical Chemistry Analyzer; Stanbio Laboratory). The assay had a minimum sensitivity of $0.13 \mathrm{mmol} / \mathrm{L}$ and an interassay CV of $5.30 \%$. Triglycerides were assessed with the glycerylphosphate colorimetric method (Sirrus Clinical Chemistry Analyzer; Stanbio Laboratory) with a minimum sensitivity of $0.06 \mathrm{mmol} / \mathrm{L}$ and an interassay CV of $4.28 \%$. Adiponectin was measured by radioimmunoassay (Millipore RIA kit, EMD Millipore, Billerica, MA). TNF- $\alpha$, IL- 6 , and hs-CRP were measured using electrochemiluminescence detection (SECTOR Imager 2400 reader; Meso Scale Diagnostics, Gaithersburg, MD). TNF- $\alpha$, IL- 6 , and hs-CRP assay had minimum sensitivities of $0.275 \mathrm{pg} / \mathrm{mL}$, $0.169 \mathrm{pg} / \mathrm{mL}$, and $0.02 \mathrm{mg} / \mathrm{L}$, respectively, and intra-assay CVs of $1.15 \%, 11.1 \%$, and $0.086 \%$, respectively.

Four estimates of insulin resistance were used in the study: fasting insulin; 2-h insulin; the homeostasis model assessment of insulin resistance (HOMA-IR); and area under the curve (AUC) for insulin. These estimates have been shown to correlate well with the more direct measures of insulin sensitivity such as the hyperinsulinemic euglycemic clamp (24). HOMA-IR was calculated as fasting insulin $(\mu \mathrm{U} / \mathrm{mL})$ multiplied by fasting glucose (mmol/L), divided by 22.5 ; AUC insulin was calculated using the trapezium rule as previously described (25).

\section{Physical activity measurement}

The Actigraph GT1M accelerometer (Actigraph, Pensacola, FL) was used to capture physical activity over a period of 7 days. During the first visit, participants were instructed on proper placement and use of the accelerometer. Participants were instructed to wear the accelerometer on the right hip during all waking hours for 7 days and to maintain usual activity habits during this time period. The accelerometer was initialized for 7 days of data collection before the participant left the 
laboratory. Epoch duration (sampling period) was set at 1 min and output was expressed as activity counts per minute and steps per minute. Data recorded over a 7-day period were automatically stored in the accelerometer and downloaded to a computer when the participant returned to the laboratory. An overall average of daily activity counts and steps from the accelerometer were obtained for days with at least $12 \mathrm{~h}$ of monitor wear or $75 \%$ coverage for a 16 -h waking day (26). Average wear time for the accelerometer was $15.6 \mathrm{~h}$.

\section{Body composition}

The percentage of body fat, fat mass, and fat-free mass was measured by dualenergy x-ray absorptiometry (Lunar DPXNT; GE Lunar, Madison, WI). Participants were asked to remove jewelry, metal objects, and shoes before the scan. The same technician positioned the participants and performed the whole-body scans. Quality assurance tests were performed every morning before scanning.

\section{Cardiorespiratory fitness measurements $\left(\mathrm{Vo}_{2}\right.$ peak)}

$\mathrm{VO}_{2}$ peak was determined using a continuous exercise test on a treadmill (Track Master $\times 425 \mathrm{C}$; Full Vision, Newton, $\mathrm{KS})$. After measuring resting expired gases for $2 \mathrm{~min}$, a 2-min warm-up was performed at $94.0 \mathrm{~m} / \mathrm{min}$. The treadmill speed was then increased to a comfortable jogging pace as determined by the participant for $2 \mathrm{~min}(147.5-174.0 \mathrm{~m} / \mathrm{min})$. The treadmill grade was then increased by $1 \%$ each minute thereafter until volitional fatigue. During the exercise test, $\mathrm{VO}_{2}, \mathrm{VCO}_{2}$, ventilation, heart rate, and respiratory rate were measured using a computerized metabolic system (TrueOne 2400; Parvo Medics, Salt Lake City, UT). Heart rate was continuously recorded using a heart rate monitor and receiver integrated with the metabolic cart (Polar Electro, Lake Success, NY). For all $\mathrm{VO}_{2}$ analyses, data were smoothed with a 15-breath moving average (27). $\mathrm{VO}_{2}$ peak was recorded as the highest $\mathrm{VO}_{2}$ obtained during the last minute of exercise.

\section{Sample size estimates and statistical analyses}

A priori sample size estimates were generated based on data from our laboratory (28). We used the SD for the independent (0.8) and dependent variables (50.6) and the slope of the regression (21.9) to calculate sample size using GPower 3.1.
Assuming a power of 0.80 and $\alpha$ of 0.05 , a sample size of 63 subjects was required to detect a significant relationship between HOMA-IR and triglyceride levels. Additionally, using multiple regression sample size calculations and estimating a small effect size (0.10), 64 subjects would result in a power of 0.80 and $\alpha$ of 0.05 .

Data were analyzed for normality and homogeneity of variance. Variables that were not normally distributed were logtransformed (triglycerides, systolic blood pressure, hs-CRP, HOMA-IR, fasting insulin, and AUC insulin). Pearson product-moment correlation analysis was used to establish associations between insulin resistance and individual cardiovascular disease risk factors and inflammatory markers. Multivariate linear regression analyses using the enter method (all independent variables entered at the same time) were used to establish the independent contributions of markers of insulin resistance on the following dependent variables: glucose; triglycerides; HDL cholesterol; blood pressure; hs-CRP; adiponectin; TNF- $\alpha$; and IL-6. Several regression models were tested and included fat mass and fat-free mass or BMI as covariates to determine if markers of insulin resistance were independently related to individual risk factors when controlling for body composition. All models included interaction terms (e.g., HOMA-IR $\times$ fat mass) as covariates. Regression diagnostics were performed and indicated there were no problems with multicolliniarity among independent variables (e.g., tolerance, condition index, and variance inflation factor). All analyses were performed using SPSS version 20.0 (SPSS, Chicago, IL). $P<0.05$ was accepted as the minimal level of significance.

\section{RESULTS}

\section{Physical and metabolic \\ characteristics of participants}

Participant characteristics are presented in Table 1. Forty-five (63\%) participants had a positive family history of type 2 diabetes, 4 (6\%) had impaired fasting glucose, 10 (14\%) had impaired glucose tolerance, 34 (48\%) had at least 1 cardiovascular disease risk factor, and only 37 (52\%) were without risk factors. Thirtyone participants (43\%) had one risk factor, two participants (3\%) had two risk factors, and one participant (1.4\%) had three or more risk factors. The most common risk factor was low HDL cholesterol, with 22 women (31\%) exhibiting this risk factor. Although all participants were classified as normal-weight based on BMI, average percentage body fat was $32 \%$, with a range of $21-45 \%$. The average HOMA-IR value was 1.3 , with a range of 0.4 to 3.2 .

\section{Simple correlations between measures of insulin sensitivity, cardiovascular disease risk factors, and inflammatory markers}

Simple correlations are presented in Table 2. Log HOMA-IR and log fasting insulin were positively correlated with fasting glucose, log triglycerides, log systolic blood pressure, and log diastolic blood pressure, and were negatively correlated with adiponectin $(P<0.05)$. Log HOMAIR and log fasting insulin were not correlated with HDL cholesterol, log hs-CRP, TNF- $\alpha$, or IL-6 $(P>0.05)$. The 2 -h insulin was positively correlated with diastolic blood pressure, log triglycerides, and log hs-CRP, but not with HDL cholesterol, log systolic blood pressure, adiponectin, TNF- $\alpha$, or IL-6 $(P>0.05)$. AUC insulin was not correlated with any of the dependent variables.

\section{Multivariate linear regression analysis to assess the independent contribution of markers of insulin resistance on cardiovascular disease risk factors and inflammatory markers}

Addition of the different body composition covariates in each model produced similar results. Results from models using fat mass and fat-free mass as covariates are presented because these variables contributed more to explained variance $\left(r^{2}\right)$ in the regression models compared with BMI. Interaction terms were not significant and were not included in the final models. Results from the multivariate regression analysis indicated that HOMA-IR and fasting insulin remained significantly and positively related to $\log$ triglycerides $(P<0.01)$, log systolic blood pressure $(P<0.05)$, diastolic blood pressure $(P<0.05)$, and fasting glucose $(P<0.05)$ (Table 3$)$ after adjustment for fat mass and fat-free mass. After adjusting for fat mass and fat-free mass, HOMA-IR and fasting insulin were no longer significantly related to adiponectin $(P>0.05)$ (Table 3), and 2-h insulin was no longer significantly related to log triglycerides, diastolic blood pressure, or log hs-CRP $(P>0.05)$. 
Table $1-$ Physical and metabolic characteristics of the participants $(\mathrm{n}=71)$

Median

Variable

Mean \pm SD

(interquartile range)

\begin{tabular}{|c|c|c|}
\hline \multicolumn{3}{|l|}{ Demographics } \\
\hline Age, years & $25.3 \pm 4.8$ & $24.0(22.0-28.0)$ \\
\hline Body mass, $\mathrm{kg}$ & $57.4 \pm 5.3$ & $57.8(53.1-61.1)$ \\
\hline Body mass index, $\mathrm{kg} / \mathrm{m}^{2}$ & $22.2 \pm 1.6$ & $22.2(21.0-23.2)$ \\
\hline Fat, \% & $32.0 \pm 5.9$ & $31.4(27.5-36.3)$ \\
\hline Fat, $\mathrm{kg}$ & $18.5 \pm 4.4$ & $18.2(15.0-21.6)$ \\
\hline Fat-free mass, kg & $38.9 \pm 3.9$ & $38.8(35.8-41.0)$ \\
\hline Physical activity (steps/day) & $6,754.0 \pm 2,191.0$ & $6,457.0(5,099.0-7,889.0)$ \\
\hline Peak oxygen consumption (L/min) & $2.2 \pm 0.4$ & $2.1(1.9-2.5)$ \\
\hline \multicolumn{3}{|l|}{ Markers of insulin resistance } \\
\hline Fasting insulin, $\mu \mathrm{U} / \mathrm{mL}$ & $5.7 \pm 2.4$ & $5.0(3.9-6.9)$ \\
\hline 2-h insulin, $\mu \mathrm{U} / \mathrm{mL}$ & $51.2 \pm 25.8$ & $46.7(33.9-66.6)$ \\
\hline AUC insulin, $\mu \mathrm{U} / \mathrm{mL}^{-1} \cdot 120 \mathrm{~min}^{-1}$ & $122.7 \pm 57.6$ & $110.4(87.1-142.6)$ \\
\hline HOMA-IR & $1.3 \pm 0.6$ & $1.1(0.9-1.6)$ \\
\hline 2-h glucose, mmol/L & $6.4 \pm 1.4$ & $6.2(5.5-7.1)$ \\
\hline AUC glucose, $\mathrm{mmol} \cdot \mathrm{L}^{-1} \cdot 120 \mathrm{~min}^{-1}$ & $13.9 \pm 2.2$ & $13.8(12.0-15.4)$ \\
\hline \multicolumn{3}{|l|}{ Cardiovascular disease risk factors } \\
\hline Waist circumference, $\mathrm{cm}$ & $76.6 \pm 6.0$ & $75.8(72.1-80.8)$ \\
\hline Fasting glucose, mmol/L & $5.0 \pm 0.4$ & $4.9(4.8-5.2)$ \\
\hline HDL cholesterol, $\mathrm{mmol} / \mathrm{L}$ & $1.5 \pm 0.3$ & $1.4(1.2-1.7)$ \\
\hline Triglycerides, mmol/L & $0.8 \pm 0.4$ & $0.8(0.6-1.1)$ \\
\hline Systolic blood pressure, $\mathrm{mmHg}$ & $105.0 \pm 8.0$ & $104.0(100.0-112.0)$ \\
\hline Diastolic blood pressure, $\mathrm{mmHg}$ & $69.0 \pm 6.0$ & $68.0(65.0-72.0)$ \\
\hline \multicolumn{3}{|l|}{ Inflammatory markers } \\
\hline $\mathrm{CRP}, \mathrm{mg} / \mathrm{L}$ & $0.9 \pm 1.1$ & $0.6(0.3-1.1)$ \\
\hline Adiponectin, $\mu \mathrm{g} / \mathrm{mL}$ & $11.7 \pm 4.5$ & $10.7(8.4-14.3)$ \\
\hline Tumor necrosis factor $\alpha, \mathrm{pg} / \mathrm{mL}$ & $4.6 \pm 1.4$ & $4.2(3.6-5.1)$ \\
\hline Interleukin $6, \mathrm{pg} / \mathrm{mL}$ & $0.9 \pm 0.8$ & $0.6(0.5-1.0)$ \\
\hline
\end{tabular}

CONCLUSIONS - The primary purpose of the study was to identify whether markers of insulin resistance were independently associated with individual cardiovascular disease risk factors and markers of inflammation in young, normal-weight, Hispanic women. Our results demonstrate that in young, normal-

weight, Hispanic women, markers of insulin resistance (HOMA-IR and fasting insulin) were significantly and positively related to individual cardiovascular disease risk factors, including fasting glucose, triglycerides, systolic blood pressure, and diastolic blood pressure, independent of body composition. Our findings

Table 2-Correlations between markers of insulin resistance and individual cardiovascular disease risk factors and inflammatory cytokines

HOMA-IR* Fasting insulin* 2-h insulin AUC insulin*

\begin{tabular}{lcccr}
\hline Fasting glucose & $0.47 \S$ & $0.33 \ddagger$ & 0.11 & 0.10 \\
Triglycerides* & $0.49 \S$ & $0.48 \S$ & $0.34 \ddagger$ & 0.23 \\
HDL cholesterol & -0.19 & -0.19 & -0.18 & -0.03 \\
Systolic blood pressure* & $0.30 \dagger$ & $0.28 \dagger$ & 0.18 & 0.08 \\
Diastolic blood pressure & $0.35 \ddagger$ & $0.33 \ddagger$ & $0.26 \dagger$ & 0.20 \\
Waist circumference* & -0.08 & -0.09 & -0.11 & 0.22 \\
High sensitivity & & & & \\
$\quad$ C-reactive protein* & 0.21 & 0.19 & $0.29 \dagger$ & 0.19 \\
Adiponectin & $-0.26 \dagger$ & $-0.24 \dagger$ & -0.21 & -0.19 \\
Tumor necrosis factor $\alpha^{*}$ & 0.01 & 0.01 & -0.03 & -0.01 \\
Interleukin 6* & 0.13 & 0.15 & -0.13 & -0.10 \\
\hline
\end{tabular}

*Log-transformed. $\dagger P<0.05 . \ddagger P<0.01 . \S P<0.001$ also indicate that markers of insulin resistance were associated with adiponectin and hs-CRP, but these relationships were attenuated when body composition was entered into the models. Forty-eight percent of normal-weight women in the current study had at least one cardiovascular disease risk factor and 14\% had impaired glucose tolerance. Our findings suggest that HOMA-IR, fasting, and 2-h insulin may be important clinical markers for identifying young, normal-weight, Hispanic women who may be at risk for development of type 2 diabetes and cardiovascular disease, and show the importance of early screening for the prevention of metabolic disease in this population. The current study extends the current body of evidence in a number of ways, including the assessment of these relationships in a relatively large sample of young, normal-weight, Hispanic women living along the Texas-Mexico border, with accurate measures of body fat by dual-energy $\mathrm{x}$-ray absorptiometry and multiple measures of insulin sensitivity.

Recent studies with ethnically diverse samples (Chinese, Japanese, Asian Indians, and Caucasians) have shown that insulin resistance is significantly related to individual risk factors of cardiovascular disease. Katsuki et al. (6) reported that insulin resistance, measured by a euglycemic hyperinsulinemic clamp, was significantly related to triglycerides in normal-weight Japanese men and women. Sandeep et al. (5) studied Asian Indians and reported HOMA-IR was significantly related to blood pressure, total cholesterol, triglycerides, and HDL cholesterol, independent of BMI. Similarly, Lin et al. (7) studied Chinese women and reported insulin resistance was associated with individual features of the metabolic syndrome, independent of BMI. In one of few studies in Hispanic women, Hanley et al. (3) demonstrated HOMA-IR was related to fasting glucose, HDL cholesterol, total cholesterol, triglycerides, and blood pressure in overweight women aged 25-64 years (mean BMI, $28.6 \mathrm{~kg} / \mathrm{m}^{2}$ ). Our study extends these findings by demonstrating these associations in young, normalweight, Hispanic women and by including markers of inflammation as risk factors. Little is known regarding the relationship between insulin resistance and individual cardiovascular disease risk factors, specifically markers of inflammation, in Hispanic women. This question is of emerging importance because the prevalence of type 2 diabetes and metabolic 
Table 3-Multiple linear regression analyses to examine the contribution of measures of insulin resistance on cardiovascular disease risk factors and inflammatory markers after adjustment for total body fat and fat-free mass

\begin{tabular}{|c|c|c|c|}
\hline$\underline{\text { Dependent variable }}$ & Independent variables & $\mathrm{B} \pm \mathrm{SE}$ of the estimate & $P$ \\
\hline \multicolumn{4}{|l|}{$R^{2}=0.250$} \\
\hline \multirow[t]{3}{*}{ Triglycerides* } & HOMA-IR & $0.103 \pm 0.039$ & 0.010 \\
\hline & Fat mass & $0.006 \pm 0.005$ & 0.176 \\
\hline & Fat-free mass & $-0.010 \pm 0.006$ & 0.064 \\
\hline \multicolumn{4}{|l|}{$R^{2}=0.104$} \\
\hline \multirow[t]{3}{*}{ Systolic blood pressure* } & HOMA-IR & $0.020 \pm 0.008$ & 0.016 \\
\hline & Fat mass & $<0.001 \pm 0.001$ & 0.794 \\
\hline & Fat-free mass & $<-0.001 \pm 0.001$ & 0.974 \\
\hline \multicolumn{4}{|l|}{$R^{2}=0.146$} \\
\hline \multirow[t]{3}{*}{ Diastolic blood pressure } & HOMA-IR & $3.285 \pm 1.426$ & 0.024 \\
\hline & Fat mass & $0.163 \pm 0.169$ & 0.338 \\
\hline & Fat-free mass & $-0.166 \pm 0.203$ & 0.416 \\
\hline \multicolumn{4}{|l|}{$R^{2}=0.223$} \\
\hline \multirow[t]{3}{*}{ Fasting glucose } & HOMA-IR & $4.610 \pm 1.320$ & 0.001 \\
\hline & Fat mass & $0.290 \pm 0.160$ & 0.068 \\
\hline & Fat-free mass & $0.180 \pm 0.190$ & 0.330 \\
\hline \multicolumn{4}{|l|}{$R^{2}=0.073$} \\
\hline \multirow[t]{3}{*}{ Adiponectin } & HOMA-IR & $-2.016 \pm 1.064$ & 0.062 \\
\hline & Fat mass & $-0.113 \pm 0.126$ & 0.372 \\
\hline & Fat-free mass & $-0.106 \pm 0.151$ & 0.484 \\
\hline \multicolumn{4}{|l|}{$R^{2}=0.250$} \\
\hline \multirow[t]{3}{*}{ Triglycerides* } & Fasting insulin & $0.025 \pm 0.009$ & 0.010 \\
\hline & Fat mass & $0.007 \pm 0.005$ & 0.140 \\
\hline & Fat-free mass & $-0.010 \pm 0.006$ & 0.081 \\
\hline \multicolumn{4}{|l|}{$R^{2}=0.094$} \\
\hline \multirow[t]{3}{*}{ Systolic blood pressure* } & Fasting insulin & $0.004 \pm 0.002$ & 0.025 \\
\hline & Fat mass & $<0.001 \pm 0.001$ & 0.697 \\
\hline & Fat-free mass & $<0.001 \pm 0.001$ & 0.959 \\
\hline \multicolumn{4}{|l|}{$R^{2}=0.130$} \\
\hline \multirow[t]{3}{*}{ Diastolic blood pressure } & Fasting insulin & $0.707 \pm 0.342$ & 0.043 \\
\hline & Fat mass & $0.185 \pm 0.169$ & 0.278 \\
\hline & Fat-free mass & $-0.168 \pm 0.207$ & 0.419 \\
\hline \multicolumn{4}{|l|}{$R^{2}=0.133$} \\
\hline \multirow[t]{3}{*}{ Fasting glucose } & Fasting insulin & $0.680 \pm 0.160$ & 0.040 \\
\hline & Fat mass & $0.340 \pm 0.160$ & 0.045 \\
\hline & Fat-free mass & $0.110 \pm 0.200$ & 0.586 \\
\hline \multicolumn{4}{|l|}{$R^{2}=0.068$} \\
\hline \multirow[t]{3}{*}{ Adiponectin } & Fasting insulin & $-0.455 \pm 0.254$ & 0.078 \\
\hline & Fat mass & $-0.126 \pm 0.126$ & 0.322 \\
\hline & Fat-free mass & $-0.110 \pm 0.153$ & 0.467 \\
\hline \multicolumn{4}{|l|}{$R^{2}=0.197$} \\
\hline Triglycerides* & 2-h insulin & $0.001 \pm 0.001$ & 0.130 \\
\hline & Fat mass & $0.008 \pm 0.005$ & 0.099 \\
\hline & Fat-free mass & $-0.011 \pm 0.006$ & 0.074 \\
\hline$R^{2}=0.101$ & & & \\
\hline Diastolic blood pressure & 2-h insulin & $0.044 \pm 0.033$ & 0.188 \\
\hline & Fat mass & $0.214 \pm 0.172$ & 0.218 \\
\hline & Fat-free mass & $-0.189 \pm 0.222$ & 0.398 \\
\hline$R^{2}=0.112$ & & & \\
\hline CRP* & 2-h insulin & $0.006 \pm 0.005$ & 0.301 \\
\hline & Fat mass & $0.036 \pm 0.029$ & 0.213 \\
\hline & Fat-free mass & $-0.049 \pm 0.037$ & 0.192 \\
\hline
\end{tabular}

B indicates unstandardized parameter estimate. ${ }^{*}$ Log-transformed. syndrome affect Hispanics disproportionately than other ethnicities $(12,13,29)$. For instance, in the United States, the risk of diagnosed diabetes and metabolic syndrome is $87 \%$ (29) and 13\% (12) higher, respectively, in Mexican Americans than in non-Hispanic whites.

The majority of studies that demonstrated a significant independent relationship between markers of insulin resistance and individual cardiovascular disease risk factors used BMI, a simple measure of obesity, as a covariate $(4,5-7)$. Very few data are available that confirm these relationships after taking into account more valid and reliable measures of obesity. The results of the current study, in which a strong association between insulin resistance and risk factors was documented in young, normalweight, Hispanic women after adjustment of body composition, represent an important extension of this literature.

A unique finding in the study was that HOMA-IR and fasting insulin were related to adiponectin; however, this relationship was attenuated when body composition was added into the regression model. These findings suggest that body composition contributes to the relationships between markers of insulin resistance and adiponectin. Adiponectin, an anti-inflammatory cytokine produced by adipose tissue, is an important regulator of insulin sensitivity in skeletal muscle and liver $(30,31)$. In addition to its beneficial effects on insulin sensitivity, adiponectin also has direct antiatherogenic and anti-inflammatory effects (31). To our knowledge, only two other studies to date have demonstrated similar relationships in Hispanic women $(3,32)$. Data from the Insulin Resistance Atherosclerosis Study (IRAS) (32) showed a significant relationship between insulin resistance and adiponectin in a cohort of multiethnic men and women. Mohan et al. (33) reported a similar relationship between adiponectin and insulin resistance in Asian Indian men and women. Our study extends these findings to young and normal-weight Hispanic women.

A significant relationship between 2-h insulin and hs-CRP was observed in normal-weight, young, Hispanic women; however, this relationship was not independent of body composition. Similarly, Marquez-Videl et al. (8) reported BMI mediated the relationship between insulin resistance (HOMA-IR and fasting insulin) and hs-CRP in middle-aged and older Caucasian men and women of Swiss 
descent. Data from the IRAS multiethnic cohort of men and women (34) also showed a strong relationship between hs-CRP and insulin resistance; however, these authors reported the relationship was independent of BMI. CRP independently predicts cardiovascular events in both men and women $(23,35)$, and levels of CRP are elevated in adults with chronic or subclinical inflammation (35). Our findings suggest that body composition may play a role in the relationship between insulin resistance and markers of inflammation, such as adiponectin and hs-CRP in normal-weight Hispanic women; however, more research is needed to confirm this finding.

In normal weight individuals, the nature of the relationships among insulin resistance, risk factors, and inflammation, and the mechanisms involved, are still unknown. We hypothesize that high levels of total body fat contributed to the significant relationship between insulin resistance and risk. Obesity is a wellrecognized risk factor for the development of insulin resistance, metabolic syndrome, and type 2 diabetes (36), and is associated with a state of chronic subclinical inflammation (22). In the current study, body fat percentage ranged from $21 \%$ to $45 \%$, with 40 women $(56 \%)$ having a body fat percentage $\geq 30 \%$. Surprisingly, only three women had a waist circumference $\geq 88 \mathrm{~cm}$, which is the risk factor cut-point for metabolic syndrome (19). Normal-weight individuals who have their fat distributed primarily centrally are thought to be more insulinresistant than normal-weight individuals with a peripheral distribution of body fat (37). Our findings suggest that total body fat, not central body fat, may be an important contributing factor to the relationship between insulin resistance and risk in normal-weight Hispanic women. However, we can only speculate to the mechanisms involved because a cause-and-effect relationship cannot be established from this cross-sectional study.

In 1981, Ruderman et al. (38) introduced the phenotype of metabolically obese normal-weight individuals. This phenotype has been defined by insulin resistance (10), central obesity (6), and metabolic syndrome (14), and is characterized by a clustering of cardiovascular disease risk factors despite a normal body weight. However, because these individuals are normal-weight, they are not aware that they are at risk. This phenotype has been identified and studied in various ethnicities; however, only one study to date included Hispanic women (14). Although the current study was not designed to identify this phenotype, our data suggest that this phenotype may be present in young Hispanic women and that early screening and intervention may be needed.

We did not find significant relationships between markers of insulin sensitivity and TNF- $\alpha$ or IL- 6 . These findings are in contrast to those reported by others who found significant relationships between insulin sensitivity and TNF- $\alpha$ (9) and IL-6 (8). The reasons for the differences in findings are unknown but may be attributable to differences in the ethnicities and age groups studied and the markers of insulin resistance used. Marquez-Vidal et al. (8) studied middle-aged to older Caucasian adults, and Olson et al. (9) used the frequently sampled intravenous glucose tolerance test in middle-aged (age, 40-69 years) African American, Hispanic, and nonHispanic white men and women.

This study has several strengths, including accurate and reliable measures of body composition by dual-energy x-ray absorptiometry and a relatively large sample of normal-weight women. However, the generalizability of these results is limited because of the fact that the participants were a convenience sample of volunteers, and it is possible that women who were at higher risk for type 2 diabetes or cardiovascular disease volunteered to participate. In addition, participants were of Mexican origin living along the TexasMexico border. Therefore, it is difficult to generalize to Hispanic women living in nonborder regions of the United States.

In summary, surrogate markers of insulin resistance were associated with individual cardiovascular disease risk factors and inflammatory cytokines in normal-weight Hispanic women. Our findings suggest that HOMA-IR, fasting, and 2-h insulin may be important clinical markers for identifying young, normalweight, Hispanic women who may be at risk for development of type 2 diabetes and cardiovascular disease. Our findings show the importance of early screening for prevention of type 2 diabetes and cardiovascular disease in this population.

Acknowledgments-This study was supported by National Institutes of Health $\mathrm{Na}$ tional Institute of Diabetes and Digestive and Kidney Diseases Grant 1SC2DK083061.

No potential conflicts of interest relevant to this article were reported.
C.A.V., X.B., C.J.E., R.Y.Z., D.O., H.R., and C.L. collected and processed data. C.A.V. and X.B. analyzed the data. C.A.V. wrote the manuscript. X.B. edited the manuscript. C.A.V. is the guarantor of this work and, as such, had full access to all the data in the study and takes responsibility for the integrity of the data and the accuracy of the data analysis.

\section{References}

1. Ruige JB, Assendelft WJ, Dekker JM, Kostense PJ, Heine RJ, Bouter LM. Insulin and risk of cardiovascular disease: a metaanalysis. Circulation 1998;97:996-1001

2. Wingard DL, Barrett-Connor EL, Ferrara A. Is insulin really a heart disease risk factor. Diabetes Care 1995;18:1299-1304

3. Hanley AJ, Williams K, Stern MP, Haffner SM. Homeostasis model assessment of insulin resistance in relation to the incidence of cardiovascular disease: the San Antonio Heart Study. Diabetes Care 2002; 25:1177-1184

4. Xun P, Liu K, Cao W, Sidney S, Williams $\mathrm{OD}$, He K. Fasting insulin level is positively associated with incidence of hypertension among American young adults: a 20-year follow-up study. Diabetes Care 2012;35: 1532-1537

5. Sandeep S, Gokulakrishnan K, Deepa M, Mohan V. Insulin resistance is associated with increased cardiovascular risk in Asian Indians with normal glucose tolerance-the Chennai Urban Rural Epidemiology Study (CURES-66). J Assoc Physicians India 2011;59:480-484

6. Katsuki A, Sumida Y, Urakawa H, et al. Increased visceral fat and serum levels of triglyceride are associated with insulin resistance in Japanese metabolically obese, normal weight subjects with normal glucose tolerance. Diabetes Care 2003:26:2341-2344

7. Lin KC, Tsai ST, Kuo SC, Tsay SL, Chou P. Interrelationship between insulin resistance and menopause on the metabolic syndrome and its individual component among nondiabetic women in the kinmen study. Am J Med Sci 2007;333:208-214

8. Marques-Vidal P, Bastardot F, von Känel $\mathrm{R}$, et al. Association between circulating cytokine levels, diabetes and insulin resistance in a population-based sample (CoLaus study). Clin Endocrinol (Oxf) 12 March 2012 [Epub ahead of print]

9. Olson NC, Callas PW, Hanley AJ, et al. Circulating levels of TNF- $\alpha$ are associated with impaired glucose tolerance, increased insulin resistance, and ethnicity: the Insulin Resistance Atherosclerosis Study. J Clin Endocrinol Metab 2012;97: 1032-1040

10. Dvorak RV, DeNino WF, Ades PA, Poehlman ET. Phenotypic characteristics associated with insulin resistance in metabolically obese but normal-weight young women. Diabetes 1999;48:2210-2214 
11. Ho RC, Davy KP, Hickey MS, Summers SA, Melby CL. Behavioral, metabolic, and molecular correlates of lower insulin sensitivity in Mexican-Americans. Am J Physiol Endocrinol Metab 2002;283: E799-E808

12. Ford ES, Giles WH, Dietz WH. Prevalence of the metabolic syndrome among US adults: findings from the third National Health and Nutrition Examination Survey. JAMA 2002;287:356359

13. Cowie CC, Rust KF, Byrd-Holt DD, et al. Prevalence of diabetes and impaired fasting glucose in adults in the U.S. population: National Health And Nutrition Examination Survey 1999-2002. Diabetes Care 2006;29:1263-1268

14. St-Onge MP, Janssen I, Heymsfield SB. Metabolic syndrome in normal-weight Americans: new definition of the metabolically obese, normal-weight individual. Diabetes Care 2004;27:2222-2228

15. Winkleby MA, Kraemer HC, Ahn DK, Varady AN. Ethnic and socioeconomic differences in cardiovascular disease risk factors: findings for women from the Third National Health and Nutrition Examination Survey, 1988-1994. JAMA 1998;280:356-362

16. Lloyd-Jones DM, Leip EP, Larson MG, et al. Prediction of lifetime risk for cardiovascular disease by risk factor burden at 50 years of age. Circulation 2006;113: 791-798

17. Stamler J, Stamler R, Neaton JD, et al. Low risk-factor profile and long-term cardiovascular and noncardiovascular mortality and life expectancy: findings for 5 large cohorts of young adult and middle-aged men and women. JAMA 1999;282:20122018

18. National Heart Lung Blood Institute, Obesity Education Initiative Expert Panel on the Identification, Evaluation, and Treatment of Obesity in Adults. Clinical guidelines on the identification, evaluation, and treatment of overweight and obesity in adults. Bethesda, MD, National Heart
Lung and Blood Institute, 1998, Report 98-4083.

19. Expert Panel on Detection, Evaluation, and Treatment of High Blood Cholesterol in Adults. Executive summary of the third report of the National Cholesterol Education Program (NCEP) expert panel on detection, evaluation, and treatment of high blood cholesterol in adults (Adult Treatment Panel III). JAMA 2001;285: 2486-2497

20. American College of Sports Medicine. ACSM's guidelines for exercise testing and prescription. 8th ed. Baltimore,MD, Lippincott Williams \& Wilkins, 2009

21. Hotamisligil GS. Inflammation and metabolic disorders. Nature 2006;444:860-867

22. Galic S, Oakhill JS, Steinberg GR. Adipose tissue as an endocrine organ. Mol Cell Endocrinol 2010;316:129-139

23. Ridker PM, Hennekens CH, Buring JE, Rifai N. C-reactive protein and other markers of inflammation in the prediction of cardiovascular disease in women. $\mathrm{N}$ Engl J Med 2000;342:836-843

24. Malita FM, Karelis AD, St-Pierre DH, et al. Surrogate indexes vs. euglycaemichyperinsulinemic clamp as an indicator of insulin resistance and cardiovascular risk factors in overweight and obese postmenopausal women. Diabetes Metab 2006; 32:251-255

25. Matthews JN, Altman DG, Campbell MJ, Royston P. Analysis of serial measurements in medical research. BMJ 1990;300: 230-235

26. Matthews CE, Ainsworth BE, Thompson RW, Bassett DR Jr. Sources of variance in daily physical activity levels as measured by an accelerometer. Med Sci Sports Exerc 2002;34:1376-1381

27. Robergs RA, Dwyer D, Astorino T. Recommendations for improved data processing from expired gas analysis indirect calorimetry. Sports Med 2010;40:95111

28. Vella CA, Zubia RY, Ontiveros D, Cruz ML. Physical activity, cardiorespiratory fitness, and metabolic syndrome in young
Mexican and Mexican-American women. Appl Physiol Nutr Metab 2009;34:10-17

29. Centers for Disease Control and Prevention. National diabetes fact sheet: $\mathrm{Na}$ tional estimates and general information on diabetes and prediabetes in the United States, 2011. Atlanta, GA, Department of Health and Human Services, 2011

30. Gustafson B. Adipose tissue, inflammation and atherosclerosis. J Atheroscler Thromb 2010;17:332-341

31. Harwood HJ Jr. The adipocyte as an endocrine organ in the regulation of metabolic homeostasis. Neuropharmacology 2012;63:57-75

32. Hanley AJ, Bowden D, Wagenknecht LE, et al. Associations of adiponectin with body fat distribution and insulin sensitivity in nondiabetic Hispanics and AfricanAmericans. J Clin Endocrinol Metab 2007; 92:2665-2671

33. Mohan V, Deepa R, Pradeepa R, et al. Association of low adiponectin levels with the metabolic syndrome-the Chennai Urban Rural Epidemiology Study (CURES4). Metabolism 2005;54:476-481

34. Festa A, D'Agostino R Jr, Howard G, Mykkänen L, Tracy RP, Haffner SM. Chronic subclinical inflammation as part of the insulin resistance syndrome: the Insulin Resistance Atherosclerosis Study (IRAS). Circulation 2000;102:42-47

35. Ridker PM, Buring JE, Cook NR, Rifai N. $\mathrm{C}$-reactive protein, the metabolic syndrome, and risk of incident cardiovascular events: an 8-year follow-up of 14719 initially healthy American women. Circulation 2003;107:391-397

36. Pittas AG, Joseph NA, Greenberg AS. Adipocytokines and insulin resistance. J Clin Endocrinol Metab 2004;89:447-452

37. Kahn SE, Hull RL, Utzschneider KM. Mechanisms linking obesity to insulin resistance and type 2 diabetes. Nature 2006:444:840-846

38. Ruderman NB, Schneider SH, Berchtold P. The "metabolically-obese," normalweight individual. Am J Clin Nutr 1981; 34:1617-1621 